(C) Г.С. Широкалова

\title{
«ДИЗАЙНЕРСКИЕ ДЕТИ» КАК ПРОФИЛАКТИКА ИНВАЛИДИЗАЦИИ ОБЩЕСТВА
}

Медикализачия человеческой жизни расширяет свои возможности и права в сферах, которые были/есть табу в координатах традиционной морали. В статье анализируется проблема конструирования будущего общества через создание «дизайнерских детей», в том числе для предотвращения инвалидизации населения с помощью биомедицинских ГМ-технологий. В отличие от ученых общественное мнение пока не готово к прогнозированию последствий, рассматривая биомедицину только как эффективный способ борьбы с болезнями. На уровне обыденного сознания нет предубеждений к исследованиям в данном направлении, лишь незначительная часть населения задумыввется об отдаленных медицинских и сочиальных последствиях данных операций. В мире всегда сущеествовали «ученые-еретики», работаюшче вне границ академий и институтов. Сегодня среди них могут быть и «биохакеры», чьи исследования финансируются частными лицами, заинтересованными в результатах для решения собственных иелей и проконтролировать их работу не в силах ни один закон, ни одно государство, Среди ученьхх всегда были люди, готовые рискнуть всем ради нового слова в науке. В средние века они или на костер, тем более не остановит научный прогресс наказание в несколько лет тюремного срока сегодня. Изменив этическиеграниџь для себя, они будут изменять мораль большинства. Пассивность общества сегодня спровоцирует политиков завтра на принятие решений, способствующих дальнейшей десакрализачии человеческого тела в самых разных направлениях.

Ключевые слова: инвалидизация общества, биомедицинские ГМ-технологии, дизайнерские дети, трансгуманизм, молодежь, общественное мнение

Ссылка при цитировании: Широкалова Г.С. «Дизайнерские дети» как профилактика инвалидизации общества // Вестник антропологии, 2021. № 1 (53). С. 91-103.

\section{Вместо введения}

Вопрос о биотехнологиях для управления репродуктивными процессами не нов. Меняются сами технологии, в которых «игры природы» все в большей степени ставятся под контроль политического и научного сообщества, соотношение сил

Широкалова Галина Сергеевна - д.соц.н., профессор, старший научный сотрудник, Приволжский филиал ФНИСЦ РАН (Н. Новгород) (117218 Москва, ул. Кржижановского, 24/35, к.5), ведущий научный сотрудник Международной междисциплинарной научно-исследовательской Лаборатории изучения мировых и региональных социальных процессов, НГЛУ им. Н.А. Добролюбова (603155 Н. Новгород, ул. Минина, 31А). Эл. почта: shirokalova@list.ru https://orcid.org/0000-0003-4089-5446 
между которыми постепенно склоняется в пользу политики. Причины ужесточения контроля - возможность формирования «био-власти», которая дает возможности создания популяции «сверх-людей», с одной стороны, и «служебных людей», с другой (Директор 2015). Но глобальность отдаленных во времени последствий, осознаваемая специалистами, ретушируется необходимостью решения ряда тактических проблем, среди которых предотвращение рождения людей с инвалидностью через корректировку генома на стадии оплодотворения. Это гуманно, поскольку спасает от неизбежных страданий, социального дискомфорта человека с ограниченными возможностями и его семью, но порождает множество других этических проблем, не говоря уже о названных выше. Однако процесс медикализации объективен и будет стимулироваться в условиях рыночной экономики не столько гуманистическими соображениями, сколько экономической и политической целесообразностью, как на уровне семьи, так и государства. Основаниями для такого вывода служат перечисленные ниже объективные закономерности.

\section{Здоровье популяции}

1. Согласно статистике $35 \%$ детей в России имеют врожденные заболевания (Статистика б.г.). Развитие здравоохранения позволяет сохранить и продлить жизнь людей даже со сложными врожденными патологиями, о чем свидетельствует тот факт, что инвалиды детства в общем числе составляют 10,4\% (Более 2019).

2. Увеличение продолжительности жизни и сопутствующей ей инвалидизации. Две трети людей старше 55 лет, имеют ограниченные возможности здоровья (ОВ3) (Звездина, Кузнециова 2019).

3. Рост обеспокоенности специалистов снижением качества человеческой популяции: неравновесная термодинамическая система, лежащая в основе жизни, в процессе социальной эволюции теряет свою устойчивость», особенно в развитых странах с высокой степенью развития медицины (Апанасенко 2015).

4. Увеличение количества людей, имеющих заболевания, но не обладающих статусом инвалида из-за ужесточения критериев, дающих право на инвалидность (Самая 2019).

\section{Экономические ресурсы государства}

1. Ухудшение качества жизни семей при появлении в ней человека с ОВЗ. По данным Левада-центра, у 28\% семей с инвалидами едва хватает денег на питание и одежду (Левада-центр 2019). Плохие условия жизни в свою очередь увеличивают число лиц с ОВ3.

2. Сложности трудоустройства людей с OB3, несмотря на квотирование рабочих мест для инвалидов (Звездина, Кузнецова 2019).

3. Ограниченность бюджетных ресурсов, выделяемых государством на социальную сферу (Данилов 2020). Например, увеличившаяся с 1 июля 2019 г. выплата трудоспособным неработающим родителям (опекунам, попечителям, усыновителям), ухаживающим за инвалидом в возрасте до 18 лет или инвалидом с детства I группы с 5500 рублей до 10 тысяч в месяц, коснулась незначительной части семей (Указ 2019).

Напомним так же, что летом 2020 г. в 114 статью Конституции РФ внесено положение, согласно которому государство «обеспечивает функционирование системы социальной защиты инвалидов» для их социальной интеграции без какой-либо 
дискриминации, что также будет стимулировать контроль репродуктивной сферы с целью уменьшения социальных обязательств, прежде всего, экономических.

Заинтересованы в предупреждении рождения детей с ОВ3 и будущие родители, поскольку осознают не только экономические риски. Рост числа людей с ОВ3 отражается в двух прямо противоположных тенденциях: с одной стороны, растет толерантность к «особенным людям», с другой - практика молчаливой дискриминации сменяется немолчаливой дискриминацией, особенно после введения в обычных школах инклюзивного образования для детей с ментальными умственными или поведенческими отклонениями (Суслова, Светлакова 2018: 74). Социологические исследования на эту тему (Итоги 2018), как правило, игнорируют проблемы снижения качества образования для детей как здоровых, так и с ОВ3, снятие ответственности с родителей за поведение детей с ОВ3 и др. Исследовать эти аспекты политически некорректно, поэтому социологи не изучают весь спектр общественного мнения, гораздо более откровенно представленного в социальных сетях.

Нельзя не учитывать и психологический тренд молодого поколения на комфортность в самом широком смысле слова: родительство не должно быть препятствием к самореализации в работе, досуге и т.д., что отражается в отказе от больных детей или в движении чайлдфри.

\section{«Дизайнерские дети» - это один из смысловых центров трансгуманизма}

Но насколько общественное мнение готово принять новые медицинские технологии? Есть ли прогнозы/предложения у тех, кто обеспокоен будущим человеческой популяции? Да, в форме научной фантастики и как первые эксперименты в разных сферах. В обобщенном виде они представлены Благотворительным фондом «Наука за продление жизни»: «Дорожная карта достижения бессмертия» называет такие направления, над которыми уже сегодня работают ученые: Крионика, Регенеративная медицина, Генная инженерия долголетия, Наномедицина, Крионика, Искусственный интеллект, Цифровое бессмертие, Киборгизация. Генная инженерия, в частности, предусматривает совершенствование методов доставки генетического материала в организм человека и использование модифицированных стволовых клеток (Серия б.г.).

На фоне этих достижений в научный оборот вошло понятие «дизайнерские дети»дети «на заказ» с заранее заданными генетическими свойствами. Речь идет не только и не столько о цвете глаз и овале лица будущих наследников. В рамках трансгуманизма ставится вопрос о создании новой популяции людей, отличающейся физическими, интеллектуальными, психологическими характеристиками (Буйнякова 2017).

Трансгуманизм - ведущий научный тренд современности и нет социальных субъектов, которые помешали бы его реализации. В 2001 г. П.Д. Тищенко писал по этому поводу: «Эта безысходность имеет то преимущество, что позволяет подойти к вопросу био-власти более спокойно... Увидеть в био-власти своеобразную «судьбу» современного человека - вызов бытия, на который необходимо иметь решимость ответить» (Тищенко 2001: 13).

Научное сообщество тоже все чаще склоняется к мнению, что «вмешательство в наследуемый геном не является морально неприемлемым», хотя выдвигает ряд условий. Так, профессор Нуффилдского совета по биоэтике Карен Юнг считает, что «во-первых, такая процедура должна привести к устранению серьезных болезней и 
улучшению физических свойств организма. Во-вторых, она не должна способствовать росту дискриминации и разделению общества» (Балаева 2018).

Проблемы социального неравенства, модификации «дара существования», биомедицинской демаркации «человек - еще не человек - уже не человек», обсуждаемые философским сообществом (Тищенко 2001: 41), не являются предметом исследования в данной статье. Нас интересует отношение населения к «дизайнерским» технологиям и готовность принять их для предотвращения врожденных заболеваний. Пока эта процедура достаточно дорога: отработанные методики появятся через 15-20 лет, но за это время рынок медтехнологий, опираясь на обозначенные выше тенденции, сможет «сфабриковать» потребность в «дизайнерских детях», как это произошло с рынком генетических тестов.

\section{«Дизайнерские дети»: первые опыты}

В 2015 г. Великобритания стала первой страной в мире, узаконившей изменение генов человека сцельюустранения рискавозникновения наследственныхзаболеваний («Дизайнерские дети» 2015). Реализация изысканий в этом направлении не заставила себя ждать. Приведем в пример эксперимент, на который решилась китайская пара, в которой муж был инфицирован ВИЧ, очень распространенный в Китае. В ноябре 2018 г. в Китае родились первые в мире генетически модифицированные дети. Эксперимент провел ученый Хэ Цзянькуй по просьбе родителей, которые боялись наследственного ВИЧ-инфицирования. На стадии эмбрионов детям удалили ген, отвечающий за передачу вируса. Аналогичные работы по технологии CRISPRCas много где проводились, но до беременности и родов их никогда не доводили. Этическая позиция Хэ заключается в том, что такие операции позволительны только тогда, когда из-за наследственных заболеваний под угрозой находится жизнь человека, на создание же «дизайнерских детей», т.е. детей с заранее заданными свойствами, должен быть наложен запрет. Поскольку в природе у европейцев и американцев наблюдается естественная мутация такого типа, которую осуществил Хэ, то была возможность установить, что она улучшает когнитивные способности и память (Мутации 2019), но сокращает продолжительность жизни (ГМО 2019). Суд приговорил ученого к трем годам тюрьмы и 430 тыс. долларов штрафа, решив, что редактирование эмбриона было незаконно (В Китае 2019). В 2019 г. появилась информация о некачественном проведении самого эксперимента (Ершов 2019).

Пока большинство государств и ученых настороженно относятся к экспериментам такого рода, считая их неэтичными, но очевидно, что ничто не остановит энтузиастов, желающих улучшить антропоморфные характеристики человека. Готово ли общество к тому, чтобы принять вмешательство в геном человека? Удивительно, но обсуждения этой проблемы в интернете после многочисленных публикаций об операции Хэ Цзянькуя не последовало.

Социологические опросы на аналогичные темы так же единичны. В качестве примера приведем исследование социальных установок россиян ИСИЭЗ НИУ ВШЭ 2003, 2006, 2009 и 2011 гг. Ю.Л. Войнилов и В.В. Полякова пришли к выводу, что происходит либерализация отношения и даже личных установок на использование биомедицинских технологий. Это проявляется в повышении доли допускающих клонирование детей для бездетных пар (с 8\% в 2003 г. до 2006 г. до 14\%), клонирования здоровых тканей человека (с 30\% в 2006 до 37\% в 2009 г.). 
Тех, кто допускает клонирование клеток, значительно больше, чем клонирование людей целиком. В таблице 1 представлены некоторые из результатов, полученных в данных исследованиях (Войнилов, Полякова 2016: 192-193).

Таблица 1

Мнение населения о допустимости инновационных технологий в 2010 г. (\% от опрошенных)

\begin{tabular}{|c|c|c|c|c|c|c|}
\hline \multirow[b]{2}{*}{$\begin{array}{l}\text { Отношение к новым технологиям } \\
\text { в } 2010 \text { г. }\end{array}$} & \multicolumn{4}{|c|}{ Одобряют } & \multirow[b]{2}{*}{ 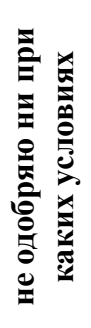 } & \multirow[b]{2}{*}{ 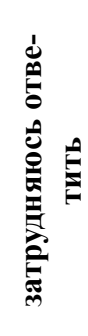 } \\
\hline & 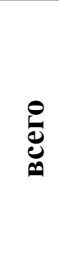 & 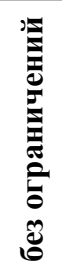 & 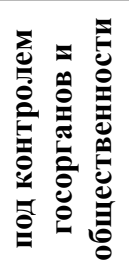 & 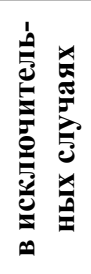 & & \\
\hline $\begin{array}{l}\text { генетическое тестирование предраспо- } \\
\text { ложенности к заболеваниям, в том числе } \\
\text { неизлечимым }\end{array}$ & 80 & 23 & 39 & 17 & 5 & 15 \\
\hline $\begin{array}{l}\text { генетические тесты детей, позволяющих } \\
\text { выявить их таланты и слабые стороны }\end{array}$ & 62 & 12 & 28 & 22 & 21 & 17 \\
\hline $\begin{array}{l}\text { клонирование животных в целях лечения } \\
\text { заболеваний человека }\end{array}$ & 61 & 8 & 29 & 24 & 24 & 15 \\
\hline $\begin{array}{l}\text { клонирование ребенка от одного из роди- } \\
\text { телей, если второй имеет серьезное гене- } \\
\text { тическое заболевание, передающееся по } \\
\text { наследству }\end{array}$ & 48 & 7 & 21 & 20 & 33 & 19 \\
\hline $\begin{array}{l}\text { Использование генетических методов } \\
\text { избавления людей от вредных привычек, } \\
\text { например, курения, алкоголизма }\end{array}$ & 78 & 25 & 36 & 17 & 8 & 14 \\
\hline $\begin{array}{l}\text { Имплантация в мозг микрочипов, позво- } \\
\text { ляющих улучшать память }\end{array}$ & 57 & 9 & 25 & 23 & 27 & 16 \\
\hline
\end{tabular}

Авторы назвали свою статью «Мое тело - моя крепость...», но данные таблицы свидетельствуют об ином: утрачивается сакральность тела. Следовательно, оно становится не крепостью, а испытательным полигоном. Это проявляется в самой разной форме: от моды на тату, несмотря на информацию о его опасности для здоровья (Широкалова 2019: 30-32). Причин можно назвать несколько, среди них утрата сакральности смерти и жизни благодаря высокой смертности населения в трудоспособном возрасте, особенно мужчин; атомизация общества, повседневность смерти от насилия в СМИ, популярность песен о смерти, увеличение верующих в «загробную жизнь» в той или иной, не обязательно религиозной, форме, ощущение несправедливости дня сегодняшнего и неуверенности в дне завтрашнем, появление в сети детских игр типа «Синий кит», примиряющих с ранним уходом из жизни.

В 2018 г., согласно опросу 5 тыс. москвичей в возрасте от 18 до 65 лет при подготовке Проекта «Москва “Умный город - 2030”», озабоченность влиянием цифровых технологий на свою жизнь высказали 4\% опрошенных, 62\% поддерживают развитие медицинских сервисов. Но были ли заданы вопросы об отношении к геномному вмешательству - неизвестно. Между тем в «Умном городе» к 2030 г. планируется геном- 
ное сканирование, что позволит разработать «генетические» цифровые платформы и наполнить их «картами генных сетей с индивидуальными проблемными дефектами, которые будут служить источниками данных для научных исследований, анализа, образовательных программ ВУЗов и машинного обучения» (Москва 2018: 10, 36).

\section{«Дизайнерский ребенок» - это здоровый ребенок?}

Китайский эксперимент дал основания поставить вопрос в ином ключе. Мы попросили студентов двух факультетов второго курса очного отделения Нижегородской государственной сельскохозяйственной академии - демографическую группу, в течение жизни которой подобные технологии станут тривиальным явлением, высказать свое отношение к вмешательству в геном эмбриона для предотвращения рождения ребенка с врожденными патологиями $(\mathrm{N}=80$ чел.). В силу возраста у респондентов нет собственной семьи, в родительских семьях нет инвалидов детства, поэтому оценки даны с абстрактных гуманистических позиций. Респонденты должны были дать мотивированные ответы на следующие открытые вопросы:

1 - отношение к экспериментам с генетическим кодом;

2 - прожективное поведение в случае угрозы заболевания собственного ребенка;

3 - вероятность изменения моральных норм в результате подобных операций;

4 - влияние эксперимента на развитие медицины;

5 - отношение к китайским родителям, согласившимся на эксперимент.

Полученные ответы были структурированы по позициям: «сторонники (оптимисты)», «противники (пессимисты)», «выжидальщики/ поживем - увидим». Из всех ответов мы выбрали, те которые представляют спектр мнений, каждое из которых имеет свою нюансировку. Гендерных отличий в оценках эксперимента и готовности к нему мы не обнаружили: женские/мужские социальные роли в современном обществе размываются, что зафиксировано многими исследователями.

По отношению к «геном-эксперименту» ответы ожидаемо разделились на три группы: относятся к этой идее однозначно отрицательно, приветствуют эксперименты, колеблются в оценках.

Позиция «противников» вмешательства в геном человека основывается на непредсказуемости результатов от медицинского вмешательства, возможных ошибках врачей. Защита от конкретной болезни не гарантирует, что взамен не появятся другие. Присутствует мотивация «креста», который человек должен нести, если ему выпала такая судьба.

Юля: Я негативно отношусь к таким экспериментам. Если у человека убрали один ген из цепочки, значит, после изъятия должны быть последствия, и неизвестно, что последствия будут положительными. Сейчас наука и медицина развивается, но нужно понимать и осознавать последствия, которые будут. Думаю, и обществу это нанесет вред. Люди будут считать, что любой недостаток можно будет убрать генетически. Я считаю, что нужно бороться с самой болезнью, а не менять генетику человека.

Нина: Я никогда об этом не задумывалась, но видимо придется. К таким экспериментам, я отношусь негативно, потому что бывает и врачебная ошибка, и т.д., поэтому это может навредить человеку.

Федор: Я отношусь к такому виду опытов над людьми отрицательно. Если 
у человека есть какая-то болезнь, нужно принять это. Полностью здоровым человек быть не может. Если нет одного, то со временем проявится другое.

Сторонники генной инженерии настроены оптимистично. Конечно, возможны ошибки, но как иначе развиваться науке? Обещаемые положительные последствия вполне оправдывают риски, неизбежные в каждом новом деле. Показательно, что девушек в этой группе нет: женщина рискует значительно больше в случае неудачного эксперимента не только здоровьем своим и ребенка, но и семьей в целом: известно, что доля разводов в случае рождения ребенка инвалида резко возрастает.

Михаил: К таким экспериментам я отношусь положительно, это шанс тех людей, которые предрасположены к разным болезням. Это шанс людей победить рак и т.д.

Александр: Мое отношение к подобному положительное. Чтобы шагнуть вперед, нужно чем-то пожертвовать.

Оценка последствий группы с выжидательной позицией более взвешенная: пока не известно соотношение положительных и отрицательных результатов лучше не рисковать.

Мария: Такие эксперименты это шаг в будущее, но это очень опасно. Это может навредить здоровой женщине, ведь до этого, она была здоровой, и неизвестно, как все пройдет. Пока не будет изучено на $100 \%$, я не соглашусь на эти опыты.

Настя: В принципе это не плохо, потому что девочек заранее оградили от таких проблем, как СПИД, но неизвестно, как потом редактирование генов повлияет на организм. Насколько мне известно, практически такие же опыты уже проводились, но после этого несколько пар обратились в клинику для лечения бесплодия. Лучше бы, конечно, не делать ничего с организмом человека, пусть мы будем оставаться такими, какими нас рожают, с болезнями, в конце концов, можно справиться.

Иван: Отношусь нейтрально. К таким экспериментам нужно относиться с огромной ответственностью, ведь в первую очередь - это жизнь человека.

Василий: Если бы в мире уже много было таких экспериментов, и они были бы положительными, то почему бы и не попробовать на себе?

Прожективная ситуация («Согласились бы Вы на вмешательство в гены в случае угрозы заболевания собственного ребенка?») заставляет человека более ответственно отнестись к оценке выбора стратегии поведения и возможных последствий. В нашем случае респонденты разделились на две группы: первая однозначно против эксперимента на своих детях, другая согласилась бы при определенных условиях.

Основные аргументы противников те же, что и при оценке таких манипуляций с геномом, но дополнительно эмоционально окрашены. Не все поняли, что речь идет о более широком поле применения коррекций, сведя это к СПИДу.

Катя: Я бы не согласилась применить это к своим детям. Потому что, не известно, чем это обернется. 
Bера: Скорее всего, нет, не провела бы на своих детях такое. Для чего? Если этот ген изъят при оплодотворении, то не факт, что потом девочки не заразятся этой болезнью.

Лариса: Я бы не стала проводить такой эксперимент, если не было бы доказано, что в дальнейшем с ними все будет хорошо, и из-за этого не возникнут отклонения.

Шура: На своих детках я не решилась бы ставить такой эксперимент. Если что-то пойдет не так, то я не хочу, чтобы они мучились из-за того, что я когда-то поставила их жизнь под угрозу.

Мотивация «согласных» провести операцию над своими детьми основывается на одном - другого выхода для спасения ребенка нет.

Алена: Может я пока не мать, мне пока этого не понять, но на эксперимент я согласилась бы (при определенных условиях). К этому можно отнестись как к опыту. Если бы мой ребенок был болен. Я не хочу рожать больного ребенка, и обрекать его на жизнь в мучениях. У меня был бы выбор: либо аборт, либо эксперимент, и я бы, скорее всего, выбрала второе.

Костя: Если это необходимо, и было бы лучше для моих детей, эксперимент имел бы гарантию, то мой ответ: «Да!».

Максим: На счет проведения таких опытов над своими детьми. Скорее «да». Но не в России, и если нет последствий.

Михаил: Если не будет другого выхода по спасению ребенка от болезни, то «да», разрешу. Если ребенок выздоровеет, то это будет просто замечательно. Умрет, тогда и я пойду за ним. Все просто...

Современная молодежь выросла в системе морального плюрализма, поэтому большинство либо не видит какой-либо угрозы для нравственности от вмешательства в геном человека, в том числе те, кто против таких экспериментов.

Борис: Никак эти эксперименты не повлияют на нормы общества. Все останется, так как есть сейчас.

Нина: Что будет с нормами морали? Я думаю, что ничего. Если это только в лучшую сторону решение проблемы.

Некоторые считают естественным, что при внедрении чего-то нового мнения разделяются.

Мария: Мораль общества изменяется по-разному. Кто-то будет «против», а кто-то «за».

Яков: Мораль ... вопрос сложный. Неизвестно, как бы отреагировал весь мир, но я в этом не вижу ничего плохого.

У некоторых сохраняется вера в возможность контроля и регулирования работы ученых.

Алена: Нормы морали, как по мне, не изменятся, а чего им меняться? Это будет сродни прививками. Хотя небольшие изменения будут, опыты над людь- 
ми все-таки. Но регулирование опытов над нами не даст ученым заиграться.

Пессимисты не уточняли, почему именно мир изменится и не в лучшую сторону.

Катя: Если бы это всегда практиковалось, то мир изменился бы не в самую лучшую сторону, т.к. повторюсь, неизвестно, к чему это приведет.

Федор: Пропадут моральные рамки в обществе.

Несмотря на сомнения и колебания при оценке вмешательства в генетику человека, опасения личного участия в таких экспериментах, респонденты согласны в том, что эксперименты в данном направлении необходимы для прогресса медицины в борьбе с болезнями.

Сергей: В мире было бы меньше болеющих, я думаю, пошла бы на пользу такая медицина, но это в том случае, если такое лечение было проверено, исследовано и т.д. Но все-таки споров было бы много по поводу методов лечения и т.д.

Борис: Будут несогласные с этим люди (как против вакцинации), будут те, кто говорит, что это замечательная практика. Далее надо смотреть, как пройдет эксперимент. Если положительно, то есть великий шанс по лечению человека от рака, СПИДа. Если отрицательно, то мы получим население либо выродков, либо вообще не получим ничего.

Николай: Это будет прорыв! Особенно, если это будет с согласия человека.

Последнее уточнение очень важно - у человека должна оставаться свобода выбора, потому что именно ему придется отвечать перед будущим ребенком.

Последний вопрос: отношение к решению китайской пары в ситуации неизведанного нейтральное: взрослый человек имеет право на любое решение.

Кира: Женщина сама пошла на это. И это ее выбор.

Костя: Мать была согласна на эксперимент, о чем еще можно говорить, это ее сугубо личный выбор. Если эксперимент пройдет хорошо, то прекрасно, если нет, то увы.

Наш опрос не ставил цели выявить соотношение сторонников и противников отношения к «дизайнерским медицинским технологиям», но получить мотивацию их приятия или отвержения молодежью. Показательны вариативность мнений, отказ от традиционных стандартов нормативности поведения, отсутствие ссылок на позиции религиозных организаций, которые наиболее однозначны в своих отрицательных оценках границ медицинского вмешательства в жизнь, «данную богом», и т.д. - свидетельствует о наличии в общественном сознании предпосылок формирования в ближайшем будущем новой суб/контр/культуры стратегического планирования «ребенка на заказ». Зафиксированы также колебания в оценках: например, принципиально отрицательное отношение к экспериментам сменяется на положительную оценку решения китайской пары.

Итак, объективность перечисленных выше процессов рано или поздно поставит проблему выбора во всей ее сложности, в том числе гуманистической. Что касается общественного мнения, то управление им с помощью новых технологий, используемых СМИ, - дело несложное. Особенно когда аргументы исходят от людей науки. К примеру, заявление д.б.н. С.Л. Киселева гасит ряд сомнений: «Половина населения 
Земли - это тоже ГМ-продукты, потому что в них проникают вирусы. Вирус папилломы, цитомегаловирус, вирус герпеса. И все мы становимся генетически модифицированными. Поэтому применять это только к этим девочкам, пожалуй, несправедливо» (Брилев 2018). По мнению биохимика, академика С.А. Лукьянова, научно-технологический прогресс уже сталкивался с барьером из этических и моральных норм, тем, что было принято считать «нормальным» в обществе. В Средние века врачи, стремившиеся изучить строение человеческого тела, могли быть убиты за осквернение тел покойных. «Но ничего, мы преодолели эту проблему и живем с высокоразвитой медициной» (Тимошенко, Лосева, Веселкова, Шунин 2018).

Но насколько корректны такие сравнения? «Исправление ошибок природы» на уровне плода, вне сомнения, гуманно. Но это частная проблема первого шага к решению более глобальной задачи. Вирус герпеса, пересадка сердца, смена пола, защита будущего ребенка от врожденных болезней не структурируют общество по критерию «сверх-люди» и «служебные люди». Такую возможность дают биотехнологии тогда, когда мутации на физиологическом уровне проводятся в условиях мутаций общественного сознания, актуализируемых через правовые и другие государственные институты. В 2003 г. Ю.В. Хен справедливо отмечала: «Евгеническая идея пронизывает всю культурную историю человечества» и в условиях приоритета интересов и блага отдельного человека над интересами общества «безотносительно к тому, как будет решена профессионалами от этики проблема последствий внедрения передовых технологий в практику, человечество в целом уже готово к своему «геномному «будущему» (Хен 2003: 3, 152). События последующих лет: открытия в науке, цинизм в политике, разрушение традиционной морали задают его контуры.

\section{Источники и материалы}

Балаева 2018 - Балаева Е. “Дизайнерские дети”: быть или не быть. https://radiovesti.ru/ brand/61178/episode/1855807/ (дата обращения: 17.04.2020).

Более 2019 - Более 12 млн инвалидов получают выплаты Пенсионного фонда. 03 декабря 2019. http://www.pfrf.ru/press_center 2019/12/03/194865 (дата обращения: 17.04.2020).

Брилев 2018 - Брилев С. “ГМО-близнецы”: китайский ученый расколол научный мир. https:// www.vesti.ru/doc.html?id=3089879. 1.12.2018 (дата обращения: 19.04.2020).

В Китае 2019 - В Китае ученого осудили на три года за эксперимент с рождением генетически модифицированных детей. https://novayagazeta.ru/news/2019/12/30/158041-v-kitae-uchenogoosudili-na-tri-goda-za-eksperiment-s-rozhdeniem-geneticheski-modifitsirovannyh-detey (дата обращения: 16.05.2020).

ГМО 2019 - ГМО-дети: озвучили печальные подробности о китайских близнецах. https://24tv. ua/health/ru/gmo_deti_ozvuchili_pechalnye_podrobnosti_o_kitajskih_bliznecah_n1162397/ 05/06/2019 (дата обращения: 17.04.2020).

Данилов 2020 - Данилов Д. Индексация социальной пенсии с апреля 2020 года: каким будет повышение. https://top-rf.ru/investitsii/302-sotsialnaya-pensiya-s-1-aprelya-povyshenie-iposlednie-novosti.html (дата обращения: 17.04.2020).

“Дизайнерские дети” 2015 - “Дизайнерские дети”: Великобритания узаконила изменение генов человека. https://www.vesti.ru/article/1730414. 25 февраля 2015 (дата обращения: 14.06.2020).

Директор 2015 - «Директор Курчатовского института М. Ковальчук выступил на заседании Совета Федерации в рамках “Времени эксперта”». 30.09.2015. http://council.gov.ru/events/ multimedia/video/44107/(дата обращения: 20.06.2020).

Ершов 2019 - Ершов А. Стали известны подробности китайского эксперимента по созданию генетически модифицированных детей (спойлер: все плохо). https://meduza.io/slides/stali- 
izvestny-podrobnosti-kitayskogo-eksperimenta-po-sozdaniyu-geneticheski-modifitsirovannyhdetey-spoyler-vse-ploho. 06.12.2019 (дата обращения: 25.04.2020).

Звездина, Кузнецова 2019 - Звездина П., Кузнецова Е. Эксперты КГИ предложили реформу системы господдержки инвалидов. https://www.rbc.ru/politics/28/05/2019/5ce817c49a7947 a6a52b8f2f. 28.05. 2019 (дата обращения: 20.06.2020).

Итоги 2018 - Итоги экспресс-опроса. http://www.inclusive-edu.ru/novosti/itogi-ekspress-opro$\mathrm{sa} /($ дата обращения: 27.04.2020).

Левада-центр: У трети семей с инвалидами едва хватает денег на еду. https://lentachel.ru/ news/2019/06/07/levada-tsentr-u-treti-semey-s-invalidami-edva-hvataet-deneg-na-edu. html\#hcq=uFisZ4s (дата обращения: 17.05.2020).

Москва 2018 - «Умный город - 2030». https://www.mos.ru/upload/alerts/files/3_Tekststrategii.pdf. Мутации 2019 - Мутации китайских ГМО-близняшек: о чем молчали ученые? https:// laba.media/materials/neozhidannye-mutatsii-kitaiskikh-gmo-blizniashek-o-chem-molchaliuchenye. 06.03.2019 (дата обращения: 20.04.2020).

Самая 2019 - «Самая зверская реформа»: государство сокращает количество инвалидов. https:/udm-info.ru/article/general/30-08-2019/samaya-zverskaya-reforma-gosudarstvosokraschaet-kolichestvo-invalidov/(дата обращения: 21.04.2020).

Серия б.г. - Серия плакатов Дорожная карта достижения бессмертия» https://www.artlebedev. ru/immortality-roadmap/ (дата обращения: 07.06.2020).

Статистика б.г. - Статистика о детях. https:/vseprodetok.ru/statistika-o-detyax/\#i(дата обращения: 17.04.2020)

Тимошенко, Лосева, Веселкова, Шунин 2018 - Тимошенко А., Лосева П., Веселкова А., Шунин И. В Китае родились первые ГМО-дети. Почему эксперимент встревожил ученых и общественность. https://nauka.tass.ru/nauka/5849815. 29.11.2018 (дата обращения: 19.04.2020).

Указ 2019 - Указ Президента Российской Федерации «О ежемесячных выплатах лицам, осуществляющим уход за детьми-инвалидами и инвалидами с детства 1 группы. http:// www.consultant.ru/cons/cgi/online.cgi? $r$ req $=$ doc \&base $=$ LAW $\& \mathrm{n}=319752 \&$ fld $=134 \& \mathrm{dst}=1000$ 000001,0\&rnd $=0.8317004290545027$ (дата обращения: 19.04.2020).

\section{Научная литература}

Апанасенко Г.Л. Биологическая деградация HOMO SAPIENS и четвертый демографический переход: пути решения проблем // Россия: тенденции и перспективы развития. Материалы XV Международной научной конференции / Отв. Ред. Ю.С Пивоваров. М.: Издательство: ИНИОН РАН, 2015. https://cyberleninka.ru/article/n/biologicheskaya-degradatsiya-homo-sapiensi-chetvyortyy-demograficheskiy-perehod-puti-resheniya-problem (дата обращения: 17.04.2020).

Буйнякова И.С. “Дизайнерские младенцы”: социально-этические проблемы биотехнологического проектирования будущих детей // Научные ведомости Белгородского государственного университета. Серия: Философия. Социология. Право. 2017. № 10. С. 130-139.

Войнилов Ю., Полякова В. Мое тело - моя крепость: общественное мнение о биомедицинских технологиях // Социология власти. 2016. Том 28. № 1. С. 185-207.

Суслова Т.Ф., Светлакова О.Ю. Исследование аттитюдов родителей в отношении инклюзивного образования детей с расстройствами аутистического спектра в отечественной и зарубежной науке // Психология. Историко-критические обзоры и современные исследования. 2018. Т. 7. № 5А. С. 68-77.

Тищенко П.Д. Био-власть в эпоху биотехнологий. М., 2001. 177 с.

Хен Ю.В. Евгенический проект: «рro» и «Contra». М., 2003. 153 с.

Широкалова Г.С. Субкультура как фактор инвалидизации // Преподавание истории в школе. 2019. № 7-2. C. 30-32. 
Shirokalova, Galina $S$ *

\section{«Designer Children» as a Way of Prevention of Social Disability}

DOI: $10.33876 / 2311-0546 / 2021-53-1 / 91-103$

The medicalization of human life expands its capabilities and rights in areas that were / are taboo in the coordinates of traditional morality. The article analyzes the problem of constructing a future society through the creation of "designer children", including prevention of disability of the population with the help of biomedical GM-technologies. Unlike scientists, public opinion is not yet ready to predict the consequences, considering biomedicine only as an effective way to fight diseases. At the level of everyday consciousness, there are no prejudices towards research in this direction, only a small part of the population thinks about the longterm medical and social consequences of these operations. There have always been "heretic scientists" in the world who work outside the boundaries of academies and institutions. Today, there may be "biohackers" among them, whose research is funded by private individuals interested in the results to achieve their own goals and not a single law, not a single state can control their work. Among scientists there have always been people who are ready to risk everything for a new word in science. In the Middle Ages, they went to the stake, so even less the punishment of several years in prison today can stop scientific progress. By changing ethical boundaries for themselves, they will change the morality of the majority. The passivity of society today will provoke politicians tomorrow to make decisions that contribute to the further desacralization of the human body in various directions.

Key words: disability of society, biomedical GM-technologies, designer children, transhumanism, youth, public opinion

For Citation: Shirokalova, G.S. 2021. «Designer Children» as a Way of Prevention of Social Disability. Herald of Anthropology (Vestnik Antropologii) 1 (53): 91-103

*Shirokalova, Galina S. - Dr. of Sociology, Prof., Senior Researcher, Volga branch of the Federal Center of Theoretical and Applied Sociology (Moscow-Nizhny Novgorod, RF), International Interdisciplinary Research Laboratory for the Study of World and Regional Social Processes (Nizhny Novgorod, RF). E-mail: shirokalova@list.ru. ORCID: https:// orcid.org/0000-0003-4089-5446

\section{References}

Apanasenko, G.L. 2015. Biologicheskaia degradatsiia HOMOSAPIENS i chetvertyi demograficheskii perekhod: puti resheniia problem [Biological degradation of HOMO SAPIENS and the fourth demographic transition: ways to solve problems]. In Rossiia: tendentsii i perspektivy razvitiia. Materialy XV Mezhdunarodnoi nauchnoi konferentsii. [Russia: trends and prospects of development. Materials of the XV International scientific conference], edited by Yu. S. Pivovarov. Moscow: Publishing House: INION RAS, 2015. https://cyberleninka.ru/article/n/biologicheskaya-degradatsiya-homo-sapiens-i-chetvyortyy-demograficheskiy-perehod-puti-resheniya-problem (date accessed: 17.04.2020).

Buyakova, I.S. 2017. "Dizainerskie mladentsy": sotsial'no-eticheskie problemy biotekhnologicheskogo proektirovaniia budushchikh detei ["Designer babies": the socio-ethical problems of biotechnological engineering of future children]. Nauchnye vedomosti Belgorodskogo gosudarstvennogo universiteta. Seriia: Filosofiia. Sotsiologiia. Pravo 10: 130-139. 
Voynilov, Yu. and V. Polyakova. 2016. Moe telo - moia krepost': obshchestvennoe mnenie o biomeditsinskikh tekhnologiiakh [My body is my fortress: public opinion on biomedical technologies]. Sotsiologiia vlasti 28 (1): 185-207.

Suslova, T.F. and O.Yu. Svetlakova. 2018. Issledovanie attitiudov roditelei v otnoshenii inkliuzivnogo obrazovaniia detei s rasstroistvami autisticheskogo spektra $\mathrm{v}$ otechestvennoi i zarubezhnoi nauke [Research of parents' attitudes towards inclusive education of children with autism spectrum disorders in domestic and foreign science]. Psikhologiia. Istoriko-kriticheskie obzory i sovremennye issledovaniia 7 (5A): 68-77.

Tishchenko, P.D. 2001. Bio-vlast' v epokhu biotekhnologii [Bio-power in the era of biotechnology]. Moscow.

Hen, Yu. V. 2003. Evgenicheskii proekt: "pro” i “Contra” [Evgenic project: "pro" and "Contra”]. Moscow.

Shirokalova G.S. 2019. Subkul'tura kak faktor invalidizatsii [Subculture as a factor of disability]. Prepodavanie istorii v shkole 7 (2): 30-32. 